\title{
Adnexal torsion: clinical, radiological and pathological characteristics in a tertiary care centre in Southern India
}

\author{
Swapna Mohan ${ }^{1} *$, Mariam Thomas ${ }^{1}$, Jayasree $\operatorname{Raman}^{2}$ \\ ${ }^{1}$ Department of Obstetrics \& Gynecology, Government Medical College, Ernakulam, Kerala, India \\ ${ }^{2}$ Department of Pathology, Government Medical College, Ernakulam, Kerala, India \\ Received: 30 July 2014 \\ Accepted: 9 August 2014 \\ *Correspondence: \\ Dr. Swapna Mohan, \\ E-mail: soppumohan@yahoo.co.in \\ (C) 2014 Mohan S et al. This is an open-access article distributed under the terms of the Creative Commons Attribution \\ Non-Commercial License, which permits unrestricted non-commercial use, distribution, and reproduction in any \\ medium, provided the original work is properly cited.
}

\begin{abstract}
Background: Adnexal torsion accounts for $2.7 \%$ of gynecological emergencies. Early diagnosis can help prevent irreversible damage to ovary. Objective of this study was to analyze the clinical, radiological and pathological characteristics of surgically proven cases of ovarian torsion.

Methods: Observational study was carried out from January 2006 to June 2014. Medical records of 38 cases of adnexal torsion were selected and analyzed retrospectively for age, parity, risk factors, clinical presentation, presence of leukocytosis, gray scale ultrasound and colour Doppler features, management, pathological results and postoperative outcome.

Results: Adnexal torsion occurred most commonly in reproductive age group (mean 27.89 years) of whom 3 were pregnant. $42 \%$ had known risk factors commonly prior pelvic surgery $(52.63 \%)$ and prior tubal ligation $(31.58 \%)$. Symptoms include sudden abdominal or pelvic pain (94.74\%), vomiting (60.53\%) and fever (21.05\%). Gray scale USG showed mixed echogenic mass $(36.84 \%)$, homogenously echogenic cyst $(34.21 \%)$ anechoic cyst $(26.32 \%)$ and free fluid $(23.68 \%)$. Doppler showed absent arterial and venous flow in $52.63 \%$. Cases were managed by detorsion \& cystectomy $(42.11 \%)$, unilateral salpingooophorectomy $(47.37 \%)$, bilateral salpingooophorectomy $(5.26 \%)$ and TAH with BSO (5.26\%). Histopathology revealed benign serous epithelial tumors $(31.58 \%)$, mucinous tumors $(21.05 \%)$, mature teratoma $(10.53 \%)$, corpus luteal cyst $(5.26 \%)$, follicular cyst $(2.63 \%)$ paraovarian cyst $(13.16 \%)$, endometriotic cyst $(2.63 \%)$ and ovarian hemangioma $(2.63 \%)$.

Conclusions: High index of suspicion \&prompt surgical intervention is necessary to preserve ovarian function even if Doppler shows vascularity. Though detorsion and cystectomy is the choice, salpingooophorectomy may be needed in infracted ovaries and older women. Higher incidence of serous \& mucinous tumors in our study suggests reappraisal of ovary sparing surgery for all patients as advocated by few.
\end{abstract}

Keywords: Adnexal torsion, Ovarian tumors, Detorsion

\section{INTRODUCTION}

Adnexal torsion is fifth most common gynecological emergency with prevalence of $2.7 \% .^{1}$ It is defined as partial or complete twisting of ovary, fallopian tube or both around it's vascular pedicle. Though it is reported in all age groups, it most commonly occurs in women of reproductive age. In early stage or partial torsion, there is slowing of venous and lymphatic return and with continued arterial perfusion hemorrhage occurs into the ovary. This will eventually result in venous and later arterial thrombosis. ${ }^{2}$ If diagnosis is delayed, hemorrhagic infarction results in non-viable ovary and sometimes lead to severe peritonitis and even death. Early diagnosis can help prevent irreversible damage to adnexal structures and allow conservative ovary sparing treatment in young women. ${ }^{3}$ 
Risk factors for ovarian torsion include ipsilateral adnexal mass $>5 \mathrm{~cm}$, pregnancy, ovulation induction, PCOS, prior tubal ligation and hyper mobility of adnexal structures. $^{1,4,5}$ Clinically patient presents with sudden onset of pelvic or abdominal pain which may be fluctuating or radiating to loin, accompanied by nausea and vomiting. Signs include pyrexia, tachycardia, generalised abdominal tenderness, tender mass in adnexa, guarding and rebound tenderness. Chance of salvaging viable ovary markedly decreases if symptoms have persisted for more than 48 hours. ${ }^{7}$ Recently a predictive score was suggested for early preoperative diagnosis. It takes into account parameters like pain duration $>8$ hours, vomiting, absence of leucorrhea/metrorrhagia and presence of ovarian cyst $>5 \mathrm{~cm}$ by USG.

Ultrasound is the initial imaging modality of choice. The spectrum of Ultrasound features depends on degree of vascular compromise. The classic grey scale ultrasound features are unilateral ovarian enlargement with hypo and hyper echoic areas in keeping with hemorrhage and necrosis, edema of ovary with peripherally arranged follicles ${ }^{1}$ and presence of echogenic free fluid in the pelvis. ${ }^{9}$ Colour Doppler shows abnormal ovarian blood flow like absence of venous flow initially and absence of arterial flow later which often indicates that ovary is not viable. ${ }^{9}$ On colour Doppler, twisted vessels within vascular pedicles are described as 'whirlpool sign'.10 When ultrasound findings in patient with suspected ovarian torsion are inconclusive, computerised tomography or magnetic resonance imaging may be helpful with good negative predictive value. ${ }^{1}$

Prompt intervention is necessary to preserve ovarian function. Detorsion is the treatment of choice in prepubescent girls and women of reproductive age, whose families are not complete, which may be combined with oophoropexy or cystectomy as necessary. ${ }^{1,11}$ In older women and in case of ovarian infarction, oophorectomy is the treatment of choice to completely remove risk of retorsion. ${ }^{1}$ However pain can be mild or intermittent in few cases and diagnosis can be challenging. Differential diagnosis include pelvic inflammatory disease, tubo ovarian abscess, appendicitis, renal colic, fibroid torsion and many more. ${ }^{1}$

With this background, the present study aims to analyze risk factors, clinical presentation, management, ultrasound and intraoperative features, histopathology and outcome in 38 cases of adnexal torsion.

\section{METHODS}

This observational study was conducted in department of obstetrics and gynecology at government medical college, a tertiary level teaching hospital in Ernakulam, Kerala, India. Sampling technique adopted here was purposive convenience sampling where in 38 cases of surgically proven ovarian torsion between January 2006 to June 2014 for a period of seven and half years were selected from medical records over 5 months and were analyzed retrospectively. The case records were examined for age, parity, risk factors, duration and nature of abdominal pain, presence or absence of vomiting, fever and palpable mass. All patients were categorized by reproductive stage into premenarchal, reproductive, peri or post-menopausal age group. Date of last menstrual period was noted. Presence of leucocytosis was also taken into consideration while analyzing. Standard transabdominal and transvaginal two dimensional ultrasound along with colour Doppler was done in 33 cases using GE LOGIC 500 MD MR3 and transabdominal 2-5 $\mathrm{MHz}$ curved array probe and transvaginal probe of $7.5 \mathrm{MHz}$. The sonograms were reviewed for imaging characteristics of ovarian vascularity, morphologic appearance, associated masses, and for intraperitoneal free fluid. Surgical notes were analyzed for site and size of ovarian cyst, number of twists, presence or absence of gangrene, ascites and surgery done. Surgical specimen was evaluated for definitive ovarian torsion and for presence of gangrene. Histopathologic evaluation of surgical specimens was obtained using standard hematoxylin-eosin staining techniques. Postoperative outcome was noted in all patients.

\section{RESULTS}

38 cases of ovarian torsion were identified. Age ranged from 13 to 80 years. Mean age was 27.89 years. Majority $26(68.42 \%)$ cases belonged to reproductive age, of whom $3(7.89 \%)$ were pregnant. $9(23.68 \%)$ cases were in perimenopausal age group of which 5 were postmenopausal. $3(7.89 \%)$ cases were prepubescent girls.

Table 1: Distribution of age.

\begin{tabular}{|llll|}
\hline $\begin{array}{l}\text { Age } \\
\text { (years) }\end{array}$ & $\begin{array}{l}\text { Number } \\
\text { of cases }\end{array}$ & $\begin{array}{l}\text { Percentage } \\
(\%)\end{array}$ & Mean \pm SD \\
\hline$<20$ & 3 & $7.89 \%$ & $13 \pm 1$ \\
\hline $21-30$ & 18 & $47.37 \%$ & $26 \pm 3.16$ \\
\hline $31-40$ & 8 & $21.05 \%$ & $36.5 \pm 2.27$ \\
\hline $41-50$ & 5 & $13.15 \%$ & $45.2 \pm 0.84$ \\
\hline $51-60$ & 1 & $2.63 \%$ & $55 \pm 0$ \\
\hline $61-70$ & 1 & $2.63 \%$ & $62 \pm 0$ \\
\hline $71-80$ & 2 & $5.26 \%$ & $75.5 \pm 6.36$ \\
\hline
\end{tabular}

Parity ranged from nulliparous to para 8 . Mean parity was 1.79 .

Table 2: Distribution of parity.

\begin{tabular}{|lll|}
\hline Parity & No. of cases & Percentage \\
\hline Nulliparous & 10 & $26.32 \%$ \\
\hline Parity 1 & 11 & $28.95 \%$ \\
\hline Parity 2 & 11 & $28.95 \%$ \\
\hline Parity 3 & 3 & $7.89 \%$ \\
\hline Parity 4 & 2 & $5.26 \%$ \\
\hline Parity $>5$ & 1 & $2.63 \%$ \\
\hline
\end{tabular}


$26(68.42 \%)$ cases had known risk factors at presentation. Most common risk factor is prior pelvic surgery, seen in $20(52.63 \%)$ cases of which $12(31.58 \%)$ patients had prior tubal ligation.

Table 3: Distribution of risk factors.

\begin{tabular}{|llll|}
\hline Risk factors & $\begin{array}{l}\text { Number } \\
\text { of cases }\end{array}$ & Percentage & $95 \%$ CI \\
\hline $\begin{array}{l}\text { Prior pelvic } \\
\text { surgery }\end{array}$ & 20 & $52.63 \%$ & $36.7-68.48$ \\
\hline $\begin{array}{l}\text { Post-partum } \\
\text { sterilization }\end{array}$ & 7 & $18.42 \%$ & $6.1-30.7$ \\
\hline $\begin{array}{l}\text { LSCS with } \\
\text { sterilization }\end{array}$ & 4 & $10.53 \%$ & $0.77-20.29$ \\
\hline $\begin{array}{l}\text { Laparoscopic } \\
\text { sterilization }\end{array}$ & 1 & $2.63 \%$ & $2.47-7.73$ \\
\hline LSCS* & 6 & $15.79 \%$ & $4.2-27.38$ \\
\hline Appendicectomy & 1 & $2.63 \%$ & $2.47-7.73$ \\
\hline Myomectomy & 1 & $2.63 \%$ & $2.47-7.73$ \\
\hline Pregnancy & 3 & $7.83 \%$ & $0.68-16.46$ \\
\hline Puerperium & 1 & $2.63 \%$ & $2.47-7.73$ \\
\hline $\begin{array}{l}\text { Polycystic } \\
\text { ovarian disease }\end{array}$ & 1 & $2.63 \%$ & $2.47-7.73$ \\
\hline $\begin{array}{l}\text { Pre-existing } \\
\text { ovarian cyst }\end{array}$ & 1 & $2.63 \%$ & $2.47-7.73$ \\
\hline
\end{tabular}

*Lower segment caesarean section

Abdominal or pelvic pain was the chief complaint in 36 (94.74\%) patients at presentation. Pain was sudden or acute in $24(63.16 \%)$ cases whereas mild or intermittent in $12(31.58 \%)$ cases.

Table 4: Symptoms \& signs.

\begin{tabular}{|lll|}
\hline Symptoms \& signs & $\begin{array}{l}\text { Number } \\
\text { of cases }\end{array}$ & $\begin{array}{l}\text { Percentage } \\
(\%)\end{array}$ \\
\hline Abdominal or pelvic pain & 36 & $94.74 \%$ \\
\hline Unilateral & 25 & $65.79 \%$ \\
\hline Bilateral & 11 & $26.32 \%$ \\
\hline Colicky/ intermittent & 12 & $31.58 \%$ \\
\hline Radiating to loin/ groin/ leg & 8 & $21.05 \%$ \\
\hline Vomiting & 23 & $60.53 \%$ \\
\hline Fever & 8 & $21.02 \%$ \\
\hline Low grade & 5 & $13.16 \%$ \\
\hline High grade & 3 & $7.89 \%$ \\
\hline Nausea & 3 & $7.89 \%$ \\
\hline Dysuria & 2 & $5.26 \%$ \\
\hline Abdominal distension & 1 & $2.63 \%$ \\
\hline Tender abdominal mass & 27 & $71.05 \%$ \\
\hline Tender adnexal mass & 9 & $23.68 \%$ \\
\hline Non tender mass & 2 & $5.26 \%$ \\
\hline
\end{tabular}

*detected only on pelvic examination
27 (71.05\%) patients had tender abdominal mass. Peritoneal signs were present in $4(10.53 \%)$ cases. Total count was elevated only in $12(31.58 \%)$ cases. Duration of pain was variable from 8 hours to few months.66.66\% cases presented with pain duration of up to 48 hours. 5 cases had pain of $>1$ week duration, some even upto 5 months.

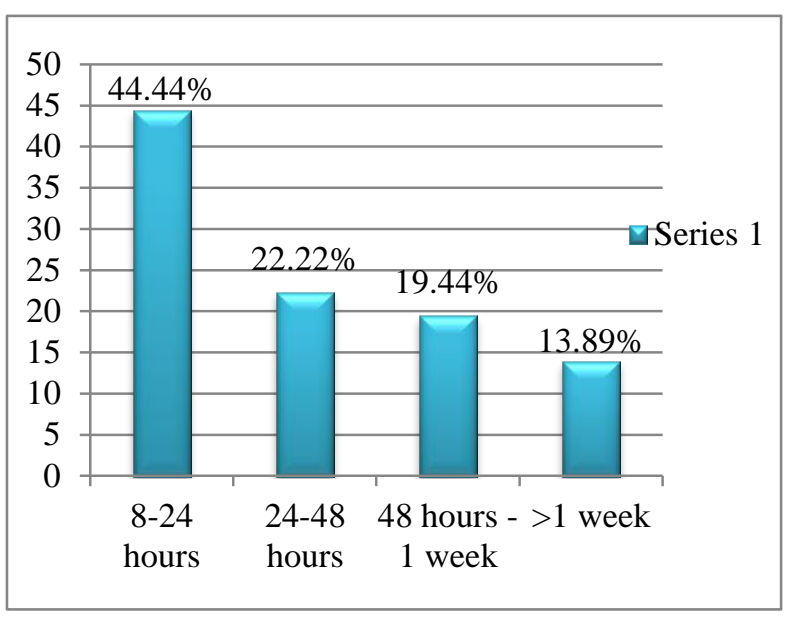

Figure 1: Duration of pain.

$11(28.95 \%)$ patients were in premenstrual phase of menstrual cycle.

Table 5: Menstrual cycle characteristics.

\begin{tabular}{|lll|}
$\begin{array}{l}\text { Menstrual } \\
\text { characteristics }\end{array}$ & $\begin{array}{l}\text { Number of } \\
\text { cases }(\mathbf{n = 2 6})\end{array}$ & $\begin{array}{l}\text { Percentage } \\
(\%)\end{array}$ \\
\hline Premenstrual & 11 & $28.95 \%$ \\
\hline Post menstrual & 4 & $10.53 \%$ \\
\hline Mid cycle & 6 & $15.79 \%$ \\
\hline Amenorrhoea & 3 & $7.89 \%$ \\
\hline Metrorrhagia & 2 & $5.26 \%$ \\
\hline
\end{tabular}

Ultrasound showed enlarged ovary in all (100\%) cases. Complex adnexal mass in $14(36.84 \%)$ cases and homogenously echogenic cyst suggestive of hemorrhage in $13(34.2 \%)$ cases were the most common findings. Colour Doppler showed absent arterial and venous flow in $20(52.63 \%)$ cases.

Table 6: Ultrasound features of twisted ovaries.

\begin{tabular}{|lll|} 
Ultrasound features & $\begin{array}{l}\text { Number } \\
\text { of cases }\end{array}$ & $\begin{array}{l}\text { Percentage } \\
(\%)\end{array}$ \\
\hline Mixed echogenic mass & 14 & $36.84 \%$ \\
\hline Homogenously echogenic cyst & 13 & $34.21 \%$ \\
\hline Anechoic cyst & 10 & $26.32 \%$ \\
\hline Solid & 1 & $2.63 \%$ \\
\hline Free fluid & 9 & $23.32 \%$ \\
\hline Absent arterial \& venous flow & 20 & $52.63 \%$ \\
\hline
\end{tabular}


Ovarian torsion was considered as diagnosis on admission in $32(84.21 \%)$ cases and surgery was done within 24 hours for these cases. In 6 cases conditions like appendicitis, urinary tract infection, ureteric colic, and pelvic inflammatory disease and acute pyelonephritis were considered initially.

At surgery left side was involved in $20(52.63 \%)$ cases, whereas right side in $18(44.74 \%)$ cases. In $2(5.26 \%)$ cases, opposite ovary was also cystic. Tumors ranged in size from 5 to $25 \mathrm{~cm}$. Majority $(47.34 \%)$ of tumours had a maximal diameter ranging from $6-10 \mathrm{~cm}$. Mean maximal diameter is $12.26 \mathrm{~cm}$.

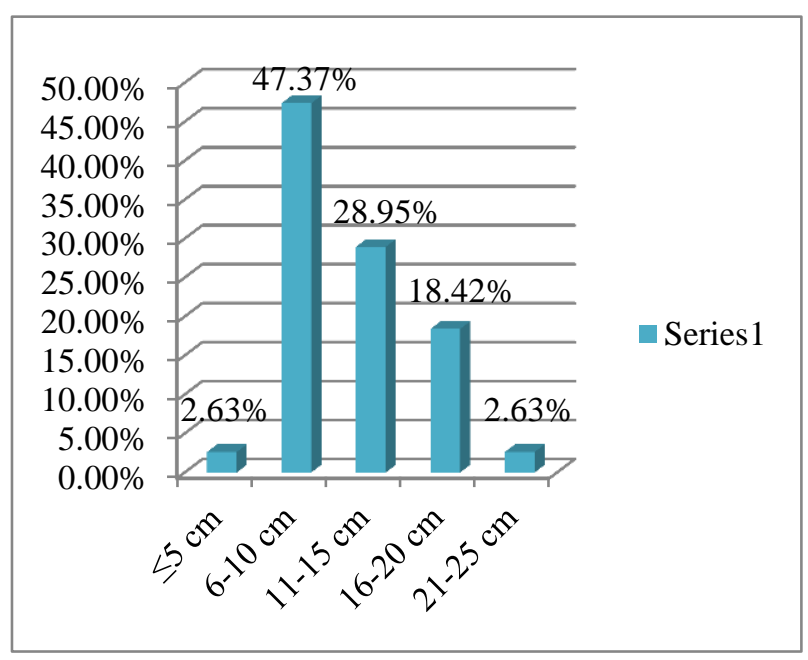

Figure 2: Size of ovarian tumors.

$19(50 \%)$ of ovarian tumors were gangrenous. Number of twists ranged from one to six with a mean of 2.42. Mean twists above which gangrene is common is 3.42 . Hemorrhagic ascites varying from $50-200 \mathrm{ml}$ was present in $13(34.21 \%)$ cases.

Table 7: Gangrene in relation to number of twists.

\begin{tabular}{|lllll|}
\hline $\begin{array}{l}\text { Number } \\
\text { of twists }\end{array}$ & $\begin{array}{l}\text { Number } \\
\text { of cases }\end{array}$ & $\begin{array}{l}\text { Percentage } \\
(\%)\end{array}$ & $\begin{array}{l}\text { Gangrene } \\
\text { present }\end{array}$ & $\begin{array}{l}\text { Gangrene } \\
\text { absent }\end{array}$ \\
\hline 1 & 11 & $28.95 \%$ & 0 & 11 \\
\hline 2 & 12 & $31.58 \%$ & 5 & 7 \\
\hline 3 & 8 & $21.05 \%$ & 7 & 1 \\
\hline 4 & 3 & $7.89 \%$ & 3 & 0 \\
\hline 5 & 2 & $5.26 \%$ & 2 & 0 \\
\hline 6 & 2 & $5.26 \%$ & 2 & 0 \\
\hline
\end{tabular}

Detorsion and cystectomy was possible in a total of 16 $(42.11 \%)$ cases of premenarchal girls and reproductive age women. Unilateral salpingooophorectomy was done in $50 \%$ of cases as they were gangrenous. In 2 perimenopausal women, opposite ovary was also cystic and hence managed by bilateral salpingo oopherectomy. 2 postmenopausal women at $>70$ years were managed by Total abdominal hysterectomy with bilateral salpingooophorectomy considering high risk of malignancy. Intra operative complications include 3 cases of bowel and 1 case of omental adhesion on to the tumor.

Table 8: Surgical management of adnexal torsion.

\begin{tabular}{|lll|}
\hline Surgery done & $\begin{array}{l}\text { Number } \\
\text { of cases }\end{array}$ & $\begin{array}{l}\text { Percentage } \\
(\%)\end{array}$ \\
\hline Detorsion \& cystectomy & 16 & $42.11 \%$ \\
\hline $\begin{array}{l}\text { Unilateral } \\
\text { Salpingooophorectomy }\end{array}$ & 18 & $47.37 \%$ \\
\hline Bilateral Salpingooophorectomy & 2 & $5.26 \%$ \\
\hline TAH with BSO & 2 & $5.26 \%$ \\
\hline
\end{tabular}

$37(97.37 \%)$ cases of ovarian tumors were benign. Most common being benign epithelial serous tumors in 12 $(31.58 \%)$ and mucinous tumors in $8(21.05 \%)$ cases. 4 $(10.53 \%)$ cases were mature teratoma. There was one case of borderline tumor. There was no case of malignancy.

Premenarchal girls in this study had serous and mucinous epithelial tumors. Tumors in 3 pregnant women included mature teratoma, papillary serous cystadenoma and mucinous cystadenoma. One case of borderline mucinous tumor was seen in a 35 year old nulliparous lady. Our study also included a rare case of hemangioma ovary in a 36 year old lady. Extensive gangrene made histopathological identification of tumors impossible in 4 $(10.53 \%)$ cases.

Table 9: Ovarian torsion - histopathology.

\begin{tabular}{|lll|}
\hline $\begin{array}{l}\text { Histopathology } \\
\text { of cases }\end{array}$ & $\begin{array}{l}\text { Number } \\
\text { Pencentage }\end{array}$ \\
$\begin{array}{l}\text { Benign serous } \\
\text { cystadenoma }\end{array}$ & 7 & $18.42 \%$ \\
\hline $\begin{array}{l}\text { Benign papillary } \\
\text { serous cystadenoma }\end{array}$ & 3 & $7.89 \%$ \\
\hline $\begin{array}{l}\text { Benign serous } \\
\text { cystadenoma fibroma }\end{array}$ & 2 & $5.26 \%$ \\
\hline $\begin{array}{l}\text { Benign mucinous } \\
\text { cystadenoma }\end{array}$ & 7 & $18.42 \%$ \\
\hline $\begin{array}{l}\text { Borderline mucinous } \\
\text { cystadenoma }\end{array}$ & 1 & $2.63 \%$ \\
\hline Mature cystic teratoma & 4 & $10.53 \%$ \\
\hline Para ovarian cyst & 5 & $13.16 \%$ \\
\hline Follicular cyst & 1 & $2.63 \%$ \\
\hline Corpus luteal cyst & 2 & $5.26 \%$ \\
\hline Endometriotic cyst & 1 & $2.63 \%$ \\
\hline Hemangioma ovary & 1 & $2.63 \%$ \\
\hline Gangrenous cyst* & 4 & $10.53 \%$ \\
\hline
\end{tabular}

*Histology not made out due to extensive gangrene

Postoperative complications occurred in 12 cases. Risk factors for complications were fever at presentation, anemia, diabetes, gangrene of the tumor, delay in diagnosis and management. 
Table 10: Post-operative complications.

\begin{tabular}{|lll|}
$\begin{array}{l}\text { Post-operative } \\
\text { complications }\end{array}$ & $\begin{array}{l}\text { Number of } \\
\text { cases }(n=12)\end{array}$ & $\begin{array}{l}\text { Percentage } \\
(\%)\end{array}$ \\
\hline Fever & 7 & $23.68 \%$ \\
\hline Wound infection & 2 & $5.26 \%$ \\
\hline Paralytic ileus & 2 & $5.26 \%$ \\
\hline Aspiration pneumonia & 1 & $2.63 \%$ \\
\hline
\end{tabular}

\section{DISCUSSION}

Adnexal torsion is a surgical emergency. Prompt accurate diagnosis and timely intervention are required to preserve vascularity and prevent ovarian necrosis. Although torsion of ovarian tumors can occur at all age groups, they were more common in the reproductive age group $(68.42 \%)$ in the present study. This may be because benign ovarian cysts are more common in this age group. More than $2 / 3^{\text {rd }}$ of cases had known risk factors, most common being prior pelvic surgery $(52.63 \%)$ and prior tubal ligation $(31.58 \%)$. This is very similar to the study by Houry et al. ${ }^{4}$ in 87 women with ovarian torsion where $40 \%$ had prior pelvic surgery and $21 \%$ had prior tubal ligation. $25 \%$ cases in his study had preexisting ovarian cysts. However in the present study only $2.63 \%$ had preexisting ovarian cysts. Only 3 cases of ovarian torsion occurred in pregnancy each at 6,16 and 28 weeks.

Clinical presentations of patients in our study were similar to those described in multiple prior studies., ${ }^{4,6,12}$ Abdominal or pelvic pain was the chief complaint in $95 \%$ cases, in which $2 / 3^{\text {rd }}$ were sudden onset. Vomiting present in $60.53 \%$ was second most reliable finding. Fever and leukocytosis are variable. However in all cases with high or low grade fever, tumors were gangrenous. $3 / 4^{\text {th }}$ of patients had tender mass palpable in abdomen and $11 \%$ had peritoneal signs. However in the 2 cases who never had pain abdomen, one presented with abdominal distension and the other with dysuria with no bacteriological evidence for urinary infection. Both the patients had a mass palpable which was non tender.

Almost half of patients in our study had pain duration of one day. Chen et al. ${ }^{7}$ in 2001 had shown that the chance of salvaging viable ovary markedly decreases if symptoms have persisted beyond 48 hours. However in our study almost half of tumors were gangrenous even though duration of pain was one day. Similarly almost half of tumors were not gangrenous even when pain lasted more than 48 hours. This may be due to partial or intermittent torsion in these patients. About $1 / 3^{\text {rd }}$ of women in our study were in premenstrual phase of cycle at the time of presentation. Relation of ovarian torsion to various phases of menstrual cycle needs to be ascertained by further studies.

All the 38 cases in our study had an enlarged ovary on ultrasound. Gray scale sonographic examination revealed mixed echogenic mass or cystic lesions with hemorrhage in $3 / 4^{\text {th }}$ of cases. In study done by Libby et al. ${ }^{12}$ in 2004 , cystic lesions were seen in $80 \%$ cases, solid masses in $5 \%$ and normal adnexa in $15 \%$. However in our study none of the cases had a normal adnexa on USG. Though Doppler flow was absent in half of the cases, it was present in other half. Similar findings were observed by Marchiech ${ }^{9}$ et al and Shadinger ${ }^{13}$ et al. in 2008 as they concluded that suspicion of ovarian torsion should be high in the setting of clinical symptoms and ovarian enlargement, regardless of presence or absence of an ovarian Doppler signal.

In a study by Lee ${ }^{14}$ et al. in $1989,67.6 \%$ of all torsions were on the right side. He proposed the presence of sigmoid colon as inhibitory factor for occurrence of torsion on the left side. Interestingly in our study more than half $(52.63 \%)$ were on the left side. In 4 cases the side of torsion was opposite to that shown on ultrasound, which means that ovary after torsion can lie towards opposite side. In half of the cases, tumors were gangrenous. In our study mean maximal diameter of tumor was $12.26 \mathrm{~cm}$, which is very much similar to study done by Lee ${ }^{14}$ et al. in 1989 and many others. Largest tumor in our study was in a 38 year old woman who presented with pain for 1 day. The tumor had a mean maximal diameter of $25 \mathrm{~cm}$, gangrenous with 6 twists and was benign papillary serous cystadenoma. Mean number of twists in our study was 2.42 , which is similar to the studies by Libby ${ }^{12}$ et al. in 2004 and Lee ${ }^{14}$ et al. in 1989. Gangrene was more common when the twists were more than 3 .

Oelner $^{11}$ et al. in 2006 in a study of ovarian torsion, concluded that despite necrotic appearance of twisted ischemic ovary, only detorsion to be done, as ovarian function is preserved in $88-100 \%$ cases. Houry ${ }^{4}$ et al. in 2001 had shown ovarian salvage rate of $9 \%$ in 87 cases. White ${ }^{6}$ et al had achieved detorsion in $31 \%$ of 52 cases. In the present study, detorsion and cystectomy was achieved in $42 \%$ cases which is even better than previous 2 studies. However no cases were managed by detorsion alone. Half of the tumors in our study were gangrenous and all were managed by salpingooophorectomy. 14 cases of detorsion with cystectomy and 2 cases of salpingooophorectomy were done via laparoscopy. The rest were managed by laparotomy.

Benign tumors constituted $97.37 \%$ of cases in our study. Borderline neoplasm was seen in one case. None of the tumors were malignant. Most common tumor associated with ovarian torsion in the present study was strangely benign serous tumors (31.58\%), particularly serous cystadenoma. Mature cystic teratoma was seen in only 4 cases. This is in contrast to study by Libby ${ }^{12}$ et al. in 2004 and Lee ${ }^{14}$ et al. in 1989 where mature teratoma was the most common tumor associated with torsion accounting for $30 \%$ and $17 \%$ respectively. Both the studies had malignant tumors. Difference may be due to higher incidence of serous tumors in our population which needs to be evaluated by larger studies in India. Our study also included a rare case of hemangioma ovary in 26 year old women who was on oral contraceptives. 
Strengths of this study are that all the data were collected by the principle investigator herself. Clinical data and surgical notes were complete in all cases. When the histopathology results were suspicious, slides were reviewed again. Limitations of this study are that secondary data was collected retrospectively. Sampling technique adopted was purposive convenient sampling. Random sampling could not be adopted due to lack of follow up. The sample size for premenarchal and postmenopausal age group is fairly small. Colour Doppler studies did not mention arterial and venous flow separately. Hence comparison was not possible.

\section{CONCLUSION}

Adnexal torsion accounts for $2.7 \%$ of all gynecological emergencies. It mostly occurs in women of reproductive age. Our data indicates that more than half of the cases occur with known risk factor, commonest being prior pelvic surgery and tubal ligation. Acute abdominal or pelvic pain and vomiting are the most reliable clinical indicators of torsion. Gray scale ultrasound typically shows complex adnexal mass or a cyst with low level echoes with absent arterial and venous Doppler. However if clinical suspicion of torsion is high, surgical exploration should not be delayed even in the presence of Doppler flow. Detorsion with cystectomy as necessary is the treatment of choice in most cases. However clinical risk factors \&geographical variation in types of ovarian tumors needs to be considered before liberalizing ovarian salvage for all, as the most common tumor in our study is Benign serous cystadenoma and not teratoma.

\section{ACKNOWLEDGEMENTS}

The author wishes to acknowledge help rendered by Dr. Divya in collecting case records from medical records department. The author also wishes to record deep sense of gratitude to the principal, government medical college, Ernakulam, for providing necessary facilities to carry out the research.

\section{Funding: No funding sources}

Conflict of interest: None declared

Ethical approval: The study was approved by the institutional ethics committee

\section{REFERENCES}

1. Emmanuel Damigos, Jemma John, Jackie Rose. An update on the diagnosis and management of ovarian torsion. Obstet Gynecol. 2012;14:229-36.
2. Nichols DH, Julian PT, Torsion of the adnexa Clin Obstet Gynecol. 1985;28:375-80.

3. Park SB, Kim JK, Kim KR, Cho KS. Imaging findings of complications and unusual manifestation of ovarian teratoma. Radiographics. 2008 JulAug;28(4):969-83.

4. Houry D, Abbott JT. Ovarian torsion: a fifteen year review. Ann Emerg Med. 2001;38:156-9.

5. Lawrence A, Ulrike M, Leslle M. Ultrasound evaluation of gynecological causes of pelvic pain. Obstet Gynecol Clin N Am. 2011;38:85-114.

6. White M, Stella J. Ovarian torsion 10 year perspective. Emerg Med Australas. 2005;17(3):2317.

7. Chen M, Chen C, Yang Y. Torsion of previously normal uterine adnexa, evaluation of correlation between pathologic changes and clinical characteristics Acta Obstet Gynecol Scand. 2001;80:58-61.

8. Cyrille Huchon, Pierre Panel, Gilles Kayem. Does this women have adnexal torsion? Hum Reprod. 2012;27:2359-64.

9. Mashiach R, Melaned N, Gilad N. Sonographic diagnosis of ovarian torsion, accuracy and predictive factors. J Ultrasound Med. 2011;30(9):1205-10.

10. Vijaya Raghavan SB. Sonographic whirlpool sign in ovarian torsion. J Ultrasound Med. 2004;23:1643-9.

11. Oelsner G, Shashar D. Adnexal torsion Clin Obstet Gynecol. 2006;49(3):459-63.

12. Libby L, Rochelle F, Rachel L. Preoperative sonographic and clinical characteristics as predictors of ovarian torsion. Clin Experiment Obstet Gynecol. 2004;31(1):34-8.

13. Shadinger LL, Andreotti RF, Kurian RL. Preoperative sonographic and clinical characteristics as predictors of ovarian torsion. J Ultrasound Med. 2008;27:7-13.

14. C. H. Lee, S. Raman, V. Sivanesaratnam. Torsion of ovarian tumors: a clinicopathological study. Int J Gynecol Obstet. 1989;28:21-5.

15. Bourquizane $\mathrm{S}$, Bibi $\mathrm{H}$. Adnexal torsion: report of 135 cases. J Gynecol Obstet Biol Reprod. 2003;32(6):535-40.

16. Hibbard LT. Adnexal torsion. Am J Obstet Gynecol. 1985;152:456-61.

DOI: $10.5455 / 2320-1770$. ijrcog20140968

Cite this article as: Mohan S, Thomas M, Raman

J. Adnexal torsion: clinical, radiological and pathological characteristics in a tertiary care centre in Southern India. Int J Reprod Contracept Obstet Gynecol 2014;3:703-8. 